\title{
SIMULASI PERANCANGAN MODEL SKEMA ANTRIAN PADA JARINGAN WAN UNTUK PENINGKATAN LAYANAN KINERJA MULTIMEDIA
}

\author{
Djoko Suprijatmono', Khoirul Mukhlis ${ }^{2}$ \\ Program Studi Teknik Elektro, Institut Sains dan Teknologi Nasional ${ }^{12}$ \\ email $^{1}$ :djokojte@gmail.com
}

\begin{abstract}
This research implements several queuing scenarios, such as FIFO (First in First out), PQ (Priority Queuing) and WFQ (Weighted Fair Queuing) on routers connected to WAN networks. Simulations are carried out using OPNET Modeler 14.5 with a WAN network topology that connects the Data Center with several different city users or clients, for QoS parameters such as packet loss, delay, and jitter in multimedia services such as FTP, video, and VoIP. The reference of QoS standard is the standard issued by ETSI (European Telecommunications Standards Institute) and ITU (International Telecommunication Union). The use of queuing scheme is also effective for reducing the value of delay and jitter for video and VoIP services, as proven in the graph that looks down from the beginning to the end. The WFQ queue scheme overall has the best QoS value, which means it provides weight with $50 \%$ on the video, $40 \%$ on the VoIP, and $10 \%$ on FTP proved effective for the design of topology and configuration in these research. Results all of queuing scheme such as FIFO, PQ, and WFQ queues generally satisfy of the QoS standards issued by ETSI and ITU, but delays in VoIP services have more value than the preferred standards but still far from the limit standards.
\end{abstract}

Keywords: WAN, QoS, FIFO, PQ, WFQ

\section{PENDAHULUAN}

Penempatan ruang server pada data center di luar kota yang terhubung pada jaringan WAN merupakan sebuah efektifitas, namun yang jadi kendala adalah bagaimana dengan kualitas layanan jika antara server dengan client terhubung dengan jaringan WAN yang sangat jauh di luar kota. Agar kualitas layanan tetap terjaga, maka harus memperhatikan aspek QoS (Quality of Service).

Skema antrian merupakan fitur pada router untuk manajemen paket yang ditransmisikan pada jaringan. Penelitian ini mengimplementasikan skema antrian FIFO (First in First Out), PQ (Priority Queuing) dan WFQ (Weighted Fair Queuing) pada router. Penelitian ini akan dilakukan analisa terhadap parameter QoS berupa packet loss, delay, dan jitter yang dibandingkan dengan standar yang dikeluarkan ETSI (European Telecommunications Standards Institute) dan ITU (International Telecommunication Union) pada layanan multimedia berupa FTP, video, dan VoIP.

\section{DASAR TEORI}

\section{Standar QoS (Quality of Services)}

ETSI (European Telecommunications Standards Institute)

European Telecommunications Standards Institute atau biasa disingkat ETSI merupakan organisasi standardisasi independen dan nonprofit yang menyediakan peralatan, operator jaringan, dan standar yang dapat digunakan secara global untuk industri telekomunikasi yang berbasis di Eropa. Berikut standar QoS yang dikeluarkan oleh ETSI [1]:

Tabel 2.1: Standar QoS oleh ETSI

\begin{tabular}{|c|c|c|c|}
\hline Category & Packet Loss & Delay & Jitter \\
\hline Perfect & $<3 \%$ & $<150 \mathrm{~ms}$ & $<1 \mathrm{~ms}$ \\
\hline Good & $<14 \%$ & $<300 \mathrm{~ms}$ & $<75 \mathrm{~ms}$ \\
\hline Medium & $<24 \%$ & $<450 \mathrm{~ms}$ & $<125 \mathrm{~ms}$ \\
\hline Poor & $>25 \%$ & $>450 \mathrm{~ms}$ & $>225 \mathrm{~ms}$ \\
\hline
\end{tabular}

\section{ITU (International Telecommunication Union)}

International Telecommunication Union atau himpunan Telekomunikasi Internasional adalah specialized agency Perserikatan Bangsa - Bangsa yang berwenang mengatur seluruh permasalahan telekomunikasi internasional [2]. 
Dengan memerhatikan semakin pentingnya telekomunikasi bagi pemeliharaan perdamaian dan pembangunan ekoniomi sosial semua negara, ITU dibentuk dengan tujuan memudahkan hubunganhubungan damai, kerja sama internasional antara bangsa-bangsa dan pembangunan ekonomi dan sosial dengan pemanfaatan jasa telekomunikasi. Berikut standar QoS yang dikeluarkan oleh ITU pada tabel 2.2:

\section{Skema Antrian \\ FIFO (First in First out)}

Router bekerja pada layer ketiga atau network layer pada model layer OSI. Pada layer ketiga, data yang berasal dari layer diatasnya (transport, session, presentation, dan application) di enkapsulasi pada satuan yang disebut paket.

Tabel 2.2 : Standar QoS oleh ITU

\begin{tabular}{|l|l|l|l|l|}
\hline \multirow{2}{*}{$\begin{array}{c}\text { Services/ } \\
\text { Application }\end{array}$} & \multirow{2}{*}{$\begin{array}{l}\text { Degree of } \\
\text { Symmetry }\end{array}$} & \multicolumn{3}{|c|}{$\begin{array}{c}\text { Key Performance Parameters and Target } \\
\text { Values }\end{array}$} \\
\cline { 3 - 5 } & End-to-End Delay & $\begin{array}{c}\text { Delay } \\
\text { Variation }\end{array}$ & $\begin{array}{c}\text { Information } \\
\text { Loss }\end{array}$ \\
\hline $\begin{array}{l}\text { Audio / } \\
\text { Conversationa } \\
\text { Voice }\end{array}$ & Two Way & $\begin{array}{c}<150 \mathrm{~ms} \text { Preferred } \\
<400 \mathrm{~ms} \text { Limit }\end{array}$ & $<1 \mathrm{~ms}$ & $<3 \%$ \\
\hline $\begin{array}{l}\text { Audio / Voice } \\
\text { Message }\end{array}$ & One Way & $\begin{array}{l}<1 \mathrm{~s} \text { Playback } \\
<2 \mathrm{~s} \text { Record }\end{array}$ & $<1 \mathrm{~ms}$ & $<3 \%$ \\
\hline $\begin{array}{l}\text { Audio / Audio } \\
\text { Streaming }\end{array}$ & One Way & $<10 \mathrm{~s}$ & $<1 \mathrm{~ms}$ & $<1 \%$ \\
\hline $\begin{array}{l}\text { Video /Video } \\
\text { Conference }\end{array}$ & Two Way & $<150 \mathrm{~ms}$ Preferred & & $<1 \%$ \\
\hline $\begin{array}{l}\text { Video / Video } \\
\text { Streaming }\end{array}$ & One Way & $<10 \mathrm{~s}$ & & $<1 \%$ \\
\hline Data & One Way & & & 0 \\
\hline
\end{tabular}

Kedatangan paket pada router berbeda - beda yang kemudian disimpan terlebih dahulu di memory router dan diatur dengan mekanisme paket yang datang lebih dahulu akan dilayani dan diterusakan dahulu menuju media transmisi berikutnya. Skema antrian FIFO tidak mengenal prioritas atau bobot sehingga paket yang diprioritaskan seperti layanan real time akan rentan terhadap delay dan jitter.

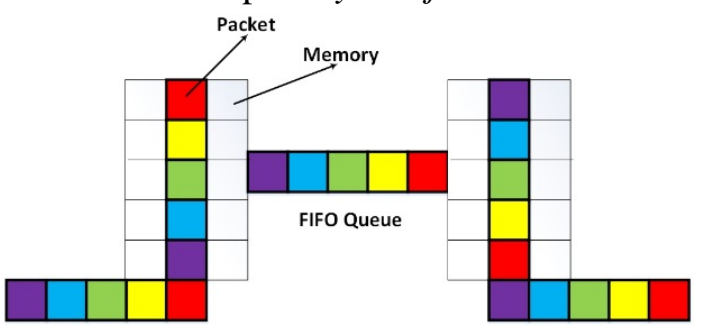

Gambar 2.1 Model Skema Antrian FIFO

\section{PQ (Priority Queuing)}

Pada skema antrian PQ, semua paket diklasifikasikan dahulu oleh memory router dan kemudian ditempatkan ke dalam antrian prioritas yang berbeda yaitu prioritas tinggi, prioritas menengah, dan prioritas rendah. Suatu paket diantrikan oleh router pada antrian awal hanya jika semua antrian dengan prioritas lebih tinggi dalam kondisi kosong. Ketika paket dengan prioritas tinggi berada pada trafik yang padat, paket dengan prioritas rendah akan tetap di hold oleh router, sehingga paket prioritas rendah memungkinkan adanya delay dan packet loss.

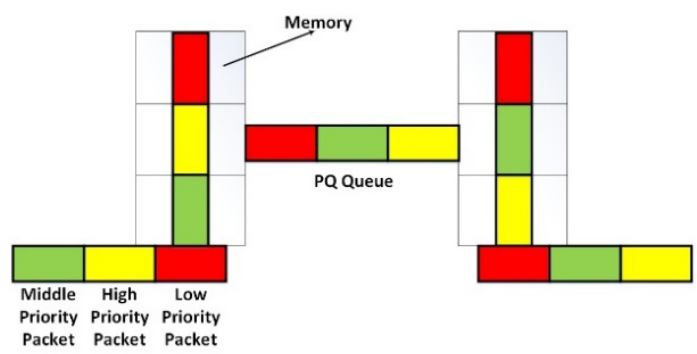

Gambar 2.2 Model Skema Antrian PQ

\section{WFQ (Weighted Fair Queuing)}

Tujuan utama dari metode WFQ adalah untuk menjamin fairness di antara semua jenis paket dengan pemberian bobot pada masing - masing klasifikasi jenis konten paket. Dalam metode antrian WFQ, paket dengan level prioritas rendah pun akan terlayani dan mendapat jaminan resources dari jaringan, paket yang bersifat real time seperti video dan VoIP dapat dikonfigurasi menggunakan bobot konten yang lebih tinggi, sehingga akan meminimalisir terjadinya packet loss, delay dan jitter.

Pada gambar 2.4 dapat terlihat bahwa administrator jaringan sebelumnya sudah mengkonfigurasi router pada skema antrian WFQ dengan bobot konten paket 50\% untuk video, 40\% untuk VoIP, dan 10\% untuk FTP. Link media transmisi memiliki bandwidth sebesar 100 mbps, kemudian datang beberapa paket layanan multimedia yaitu paket video sebesar $600 \mathrm{mb}$, paket VoIP sebesar $400 \mathrm{mb}$, dan paket FTP sebesar $500 \mathrm{mb}$. Secara otomatis memory router akan memecah paket berdasarkan persentase pembagian bobot sesuai bandwidth link media transmisi. Paket video akan dikirimkan pertama sebesar $500 \mathrm{mb}$, dilanjut dengan paket VoIP sebesar $400 \mathrm{mb}$, kemudian paket FTP sebesar $100 \mathrm{mb}$, kemudian paket video yang tersisa yaitu $100 \mathrm{mb}$, dan terakhir paket FTP yang tersisa sebesar $400 \mathrm{mb}$.

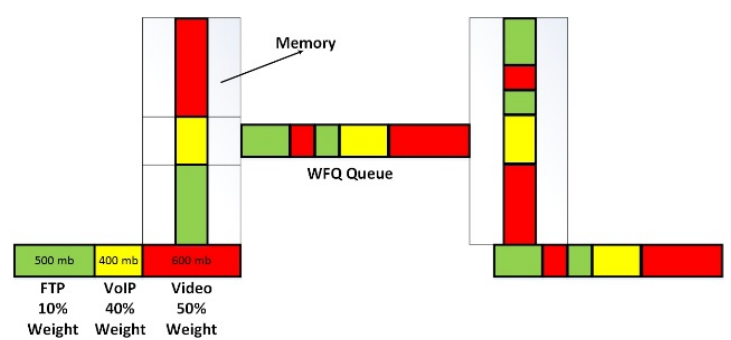

Gambar 2.3 Model Skema Antrian WFQ 


\section{PERANCANGAN DAN SIMULASI}

Berikut urutan diagram alir dari penelitian ini:

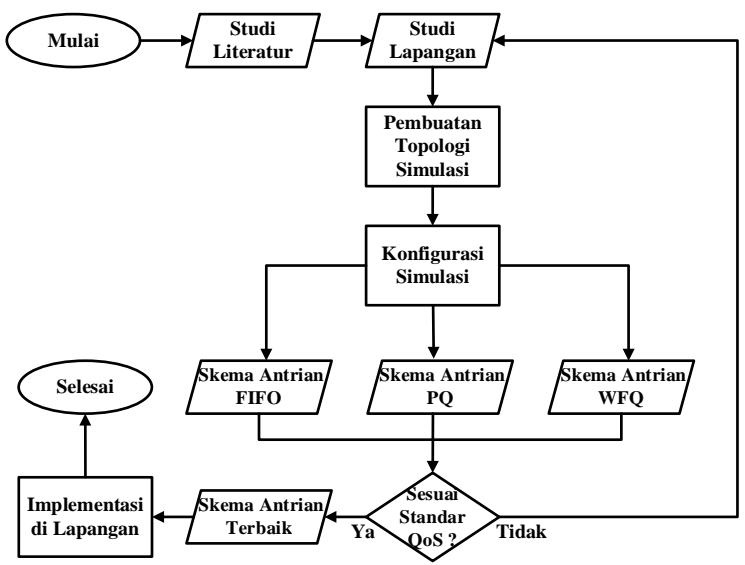

Gambar 3.1 Diagram Flowchart Penelitian Skripsi

\section{Pemodelan Jaringan}

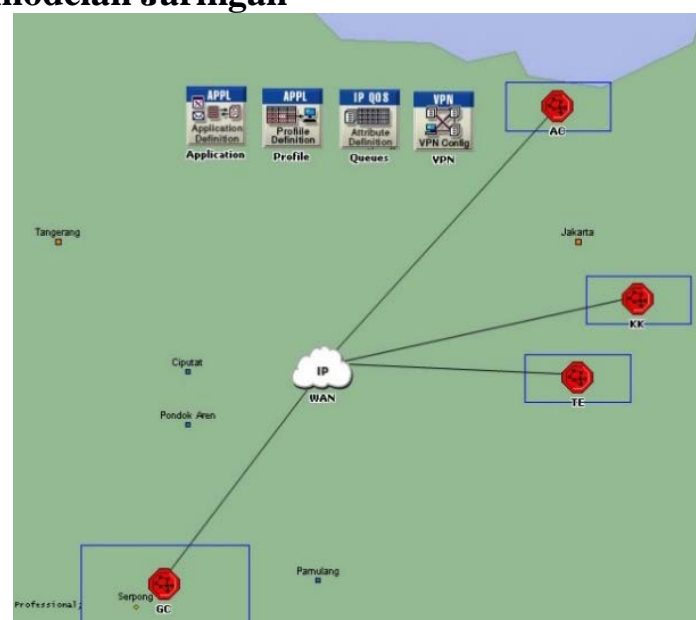

Gambar 3.2 Topologi Jaringan yang Dirancang pada Opnet Modeler

Gambar 3.2 merupakan sebuah topologi infrastruktur jaringan WAN (Wide Area Network) yang menghubungkan server di Data Center gedung German Center di kawasan Serpong BSD Tangerang yang selanjutnya akan disingkat dengan GC, yang terhubung dengan ketiga site client yaitu gedung The East di kawasan Mega Kuningan Jakarta Selatan yang selanjutnya akan disingkat dengan TE, gedung Kota Kasablanka di jalan Kasablanka Jakarta Selatan yang selanjutnya akan disingkat KK, dan gedung perkantoran di kawasan Ancol Jakarta Utara yang selanjutnya akan disingkat AC. Gedung GC merupakan bangunan penyedia jasa Data Center, gedung TE adalah kantor pusat client, sedangkan gedung $\mathrm{KK}$ dan $\mathrm{AC}$ adalah kantor cabang yang terhubung dengan jaringan WAN. Masing - masing site dan semua node perangkat dalam site terhubung dengan link 100 BaseT yang mewakili bandwith sebesar 100 Mbps.

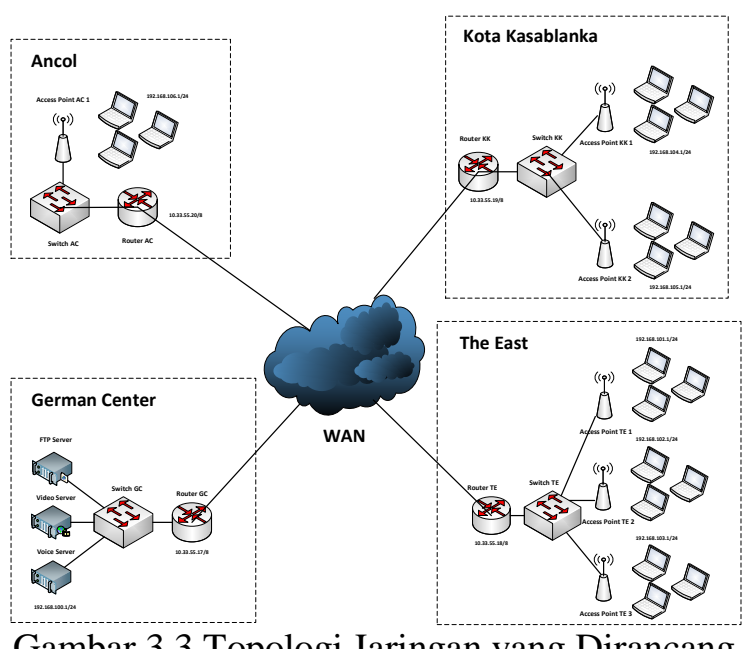

Gambar 3.3 Topologi Jaringan yang Dirancang

Server untuk melayani layanan multimedia terdapat pada German Center dan layanan dirahkan kepada client yang terdapat di The East, Kota Kasablanka, dan Ancol. Router pada semua site terhubung dengan cloud jaringan WAN.

Pada site GC terdapat satu router yang berfungsi untuk menghubungkan site dengan cloud jaringan WAN, satu switch, dan tiga server yaitu FTP server, video server, dan VoIP server.

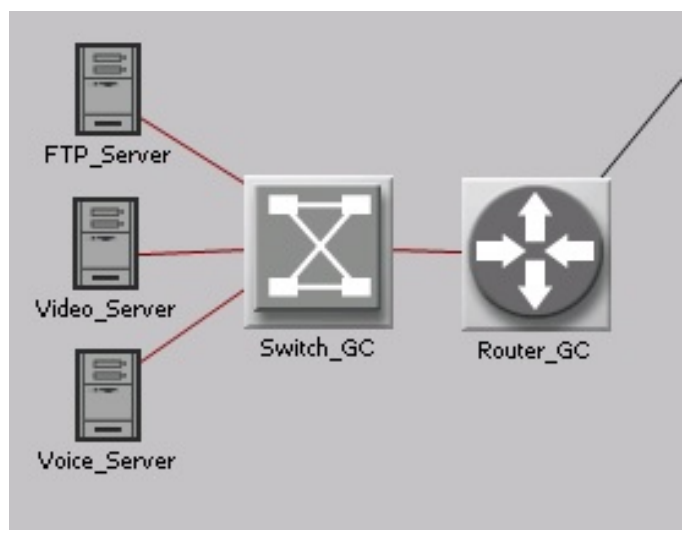

Gambar 3.4 Topologi Site GC

Pada site TE terdapat satu router yang berfungsi untuk menghubungkan site dengan cloud jaringan WAN, satu switch, dan tiga BSS yang mewakili ketiga area access point yang digunakan dalam kantor gedung.

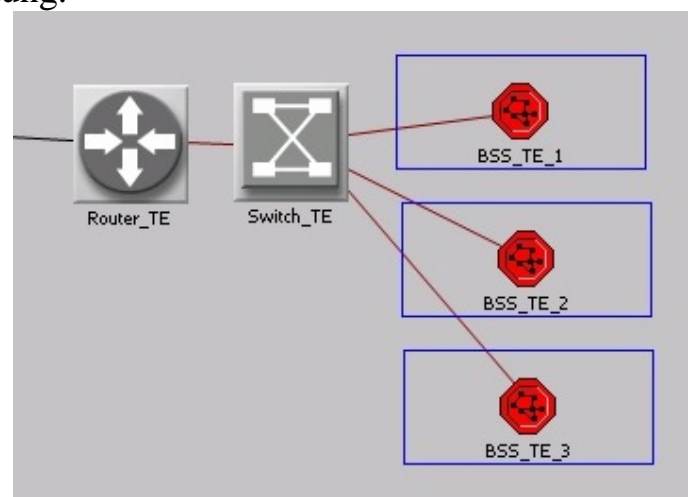

Gambar 3.5 Topologi Site TE 
Pada site KK terdapat satu router yang berfungsi untuk menghubungkan site dengan cloud jaringan WAN, satu switch, dan dua BSS yang mewakili kedua area access point yang digunakan dalam kantor gedung.

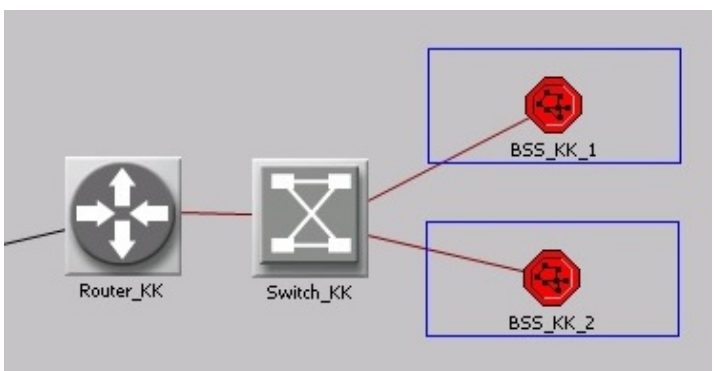

Gambar 3.6 Topologi Site KK

Pada site AC terdapat satu router yang berfungsi untuk menghubungkan site dengan cloud jaringan WAN, satu switch, dan satu BSS yang mewakili area access point yang digunakan dalam kantor gedung.

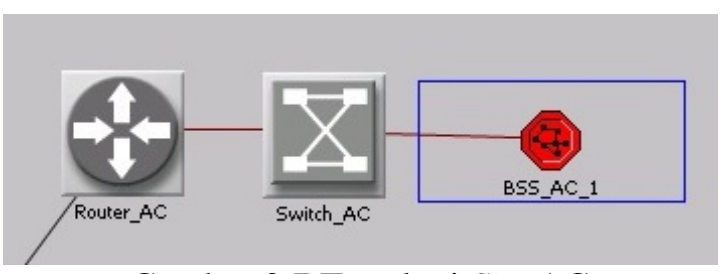

Gambar 3.7 Topologi Site AC

\subsection{Konfigurasi dan Alokasi IP Address}

Untuk dapat terhubung dan komunikasi satu sama lain, masing - masing perangkat pada jaringan harus dilakukan pengaturan IP address. Keseluruhan terdapat 7 segment IP address, yaitu 1 segment untuk server pada site GC, 3 segment untuk client yang terhubung dengan 3 access point pada site TE, 2 segment untuk client yang terhubung dengan 2 access point pada site $\mathrm{KK}$, dan 1 segment untuk client yang terhubung dengan sebuah access point pada site KK.

Router pada masing - masing site juga dilakukan pengaturan IP address agar dapat terhubung dengan jaringan WAN. Berikut pembagian alokasinya:

\begin{tabular}{|c|c|c|c|c|}
\hline Site & $\begin{array}{c}\text { Router } \\
\text { IP }\end{array}$ & $\begin{array}{c}\text { Alokasi } \\
\text { IP }\end{array}$ & $\begin{array}{c}\text { Subnet } \\
\text { Mask }\end{array}$ & $\begin{array}{c}\text { Default } \\
\text { Gateway }\end{array}$ \\
\hline German & 10.33 .55 & 192.168 & 255.255192 .168 .100 \\
Center & $17 / 8$ & $100.1 / 24$ & 255.0 & 254 \\
\hline & & 192.168. & 255.255192 .168 .101 \\
& & $101.1 / 24$ & 255.0 & 254 \\
The East & 10.33 .55$. & 192.168. & 255.255192 .168 .102 \\
& $18 / 8$ & $102.1 / 24$ & 255.0 & 254 \\
& & 192.168. & 255.255192 .168 .103 \\
& & $103.1 / 24$ & 255.0 & 254 \\
\hline Kota & 10.33 .55$. & 192.168. & 255.255192 .168 .104 \\
Kasablanka & $19 / 8$ & $104.1 / 24$ & 255.0 & 254 \\
\hline
\end{tabular}

\begin{tabular}{|c|c|c|c|c|}
\hline & & 192.168 & 255.255 & 92.168 .105 \\
& & $105.1 / 24$ & 255.0 & 254 \\
\hline \multirow{2}{*}{ Ancol } & 10.33 .55$. & 192.168 & 255.255 & 92.168 .106 \\
& $20 / 8$ & $106.1 / 24$ & 255.0 & 254 \\
\hline
\end{tabular}

\section{Konfigurasi Aplikasi Layanan Multimedia}

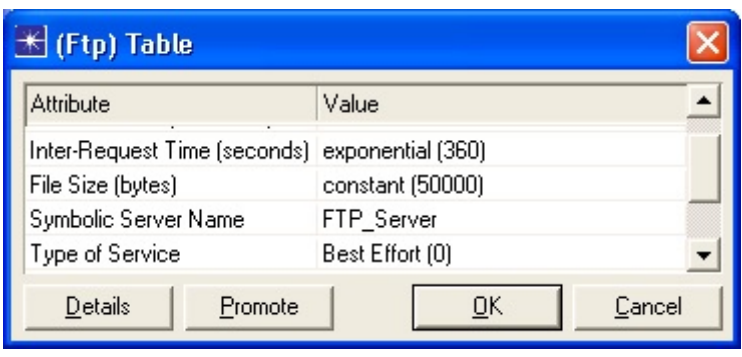

Gambar 3.8 Konfigurasi Aplikasi FTP

Berikut merupakan konfigurasi aplikasi FTP. Asumsi file sharing menggunakan file Microsoft Office dengan kapasitas rata - rata $50 \mathrm{~KB}$ yang diakses dengan rata - rata waktu 6 menit. Pada pengaturan Type of Service menggunakan Best Effort (0) yang berarti FTP merupakan prioritas terakhir setelah VoIP dan video dalam antrian.

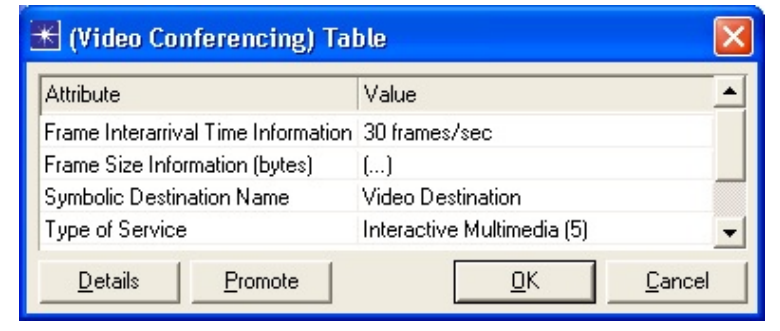

Gambar 3.9 Konfigurasi Aplikasi Video

Berikut merupakan konfigurasi aplikasi Video yang dilakukan setelah mendefinisikan layanan FTP. Konfigurasi tersebut menggunakan pengaturan VCR Quality Video yang berarti video dengan resolusi besar yang mempunyai frame interarrival time information sebesar 30 fps. Nilai Type of Service menggunakan Interactive Multimedia (5) yang berarti bahwa video merupakan prioritas kedua setelah VoIP dalam sistem antrian.

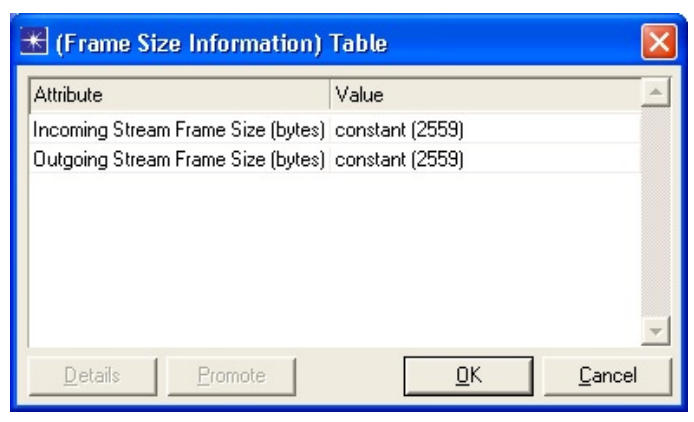

Gambar 3.10 Video Frame Size 
Untuk pengaturan Video Frame Size Information menggunakan nilai incoming dan outgoing yang konstan sebesar 2559 bytes sesuai standar video conferencing H.323.

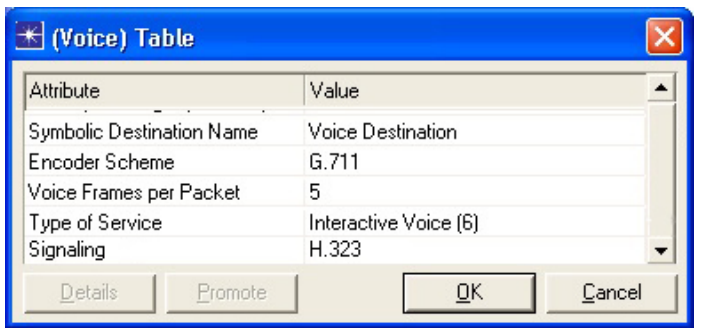

Gambar 3.11 Konfigurasi Aplikasi VoIP

Dapat dilihat bahwa konfigurasi aplikasi VoIP menggunakan codec G.711 dan Voice Frames per Packet bernilai 5 sesuai standar signaling voice H.323. Nilai Type of Service menggunakan Interactive Voice (6) yang berarti bahwa VoIP merupakan prioritas utama dalam sistem antrian.

\section{Konfigurasi Skema Antrian}

Penelitian ini menggunakan tiga skema antrian yaitu FIFO (First in First Out), PQ (Priority Queuing), dan WFQ (Weighted Fair Queuing). Dari ketiga skema antrian tersebut hanya WFQ yang dilakukan konfigurasi secara custom untuk pemberian nilai bobot, sedangkan untuk FIFO dan PQ tidak dilakukan konfigurasi apapun melainkan hanya dibuat secara default Opnet.

Pemberian bobot pada skema antrian WFQ, layanan video diberikan bobot sedikit lebih besar dari layanan VoIP untuk mencapai skema antrian yang bersifat fair, karena secara prioritas layanan video menempati prioritas kedua setelah layanan VoIP. Layanan video diberi bobot 50, layanan VoIP diberi bobot 40, dan layanan FTP diberi bobot 10 .

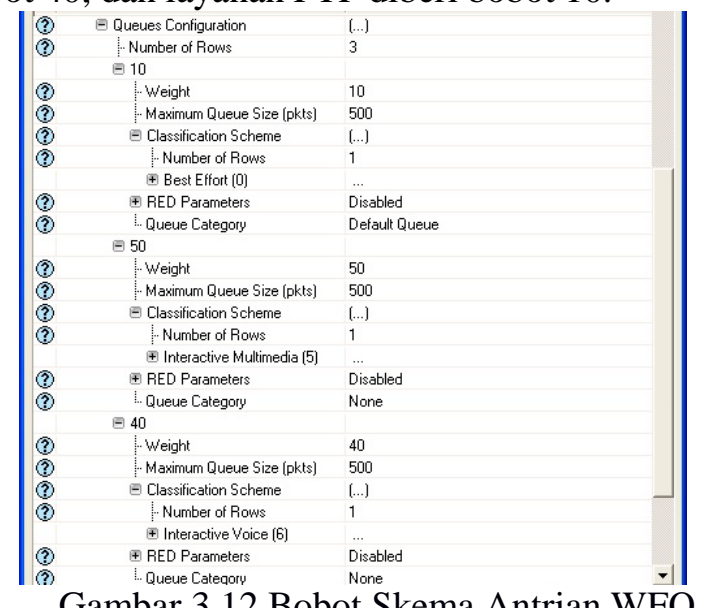

Gambar 3.12 Bobot Skema Antrian WFQ

Setelah melakukan konfigurasi bobot pada skema antrian WFQ, berikutnya dilakukan duplikat skenario untuk membentuk beberapa skenario dengan skema antrian yang berbeda. Langkah selanjutnya adalah konfigurasi skema antrian jaringan WAN, klik kiri link jaringan WAN yang terhubung dengan Cloud, kemudian memilih menu Protocols - IP QOS - Configure QOS.

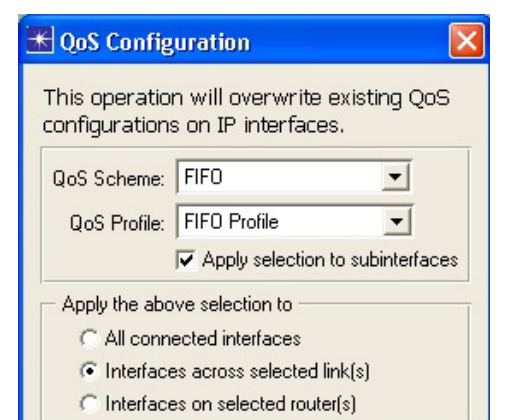

Gambar 3.13 FIFO untuk skenario 1

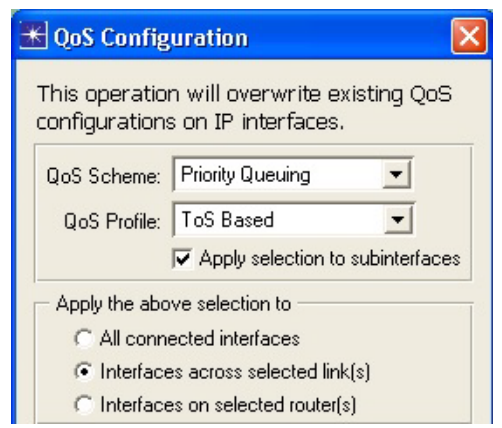

Gambar 3.14 PQ untuk skenario 2

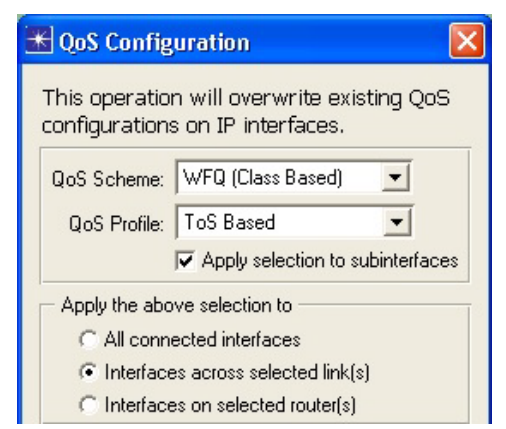

Gambar 3.15 WFQ untuk skenario 3

\section{Pemilihan Statistik Parameter}

Setelah semua konfigurasi dilakukan maka berikutnya adalah memilih statistik parameter yang nantinya akan dianalisa. Penelitian ini menggunakan Global Statistic untuk mencari parameter yang dibutuhkan pada analisis yaitu packet loss, delay, dan jitter, yang berarti statistik parameter yang dihasilkan adalah nilai rata - rata keseluruhan secara global. Parameter packet loss menggunakan statistik traffic sent dan traffic received yang nantinya dilakukan pengukuran berupa rumus untuk mendapatkan nilai packet loss, parameter delay menggunakan statistik packet end to end delay, dan parameter jitter menggunakan statistik packet delay variation. 


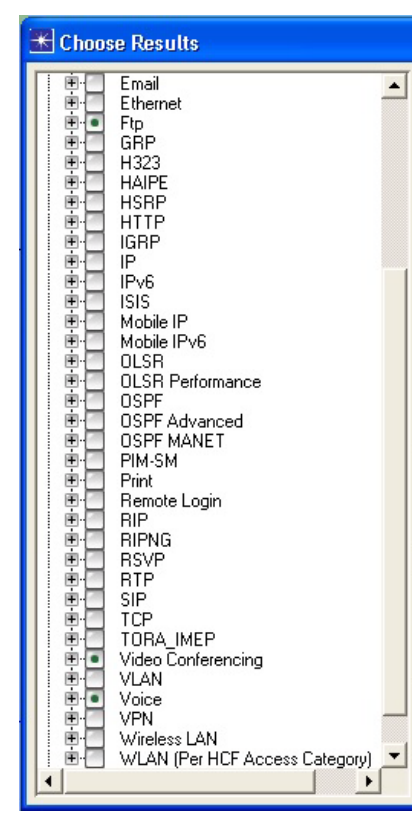

Gambar 3.16 Pemilihan Statistik Parameter

\section{ANALISA HASIL SIMULASI}

\subsection{Layanan FTP}

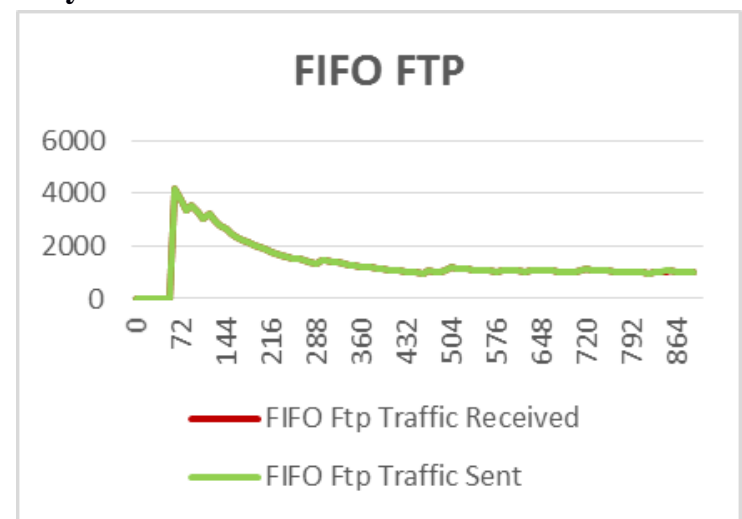

Gambar 4.1 FTP Traffic pada FIFO

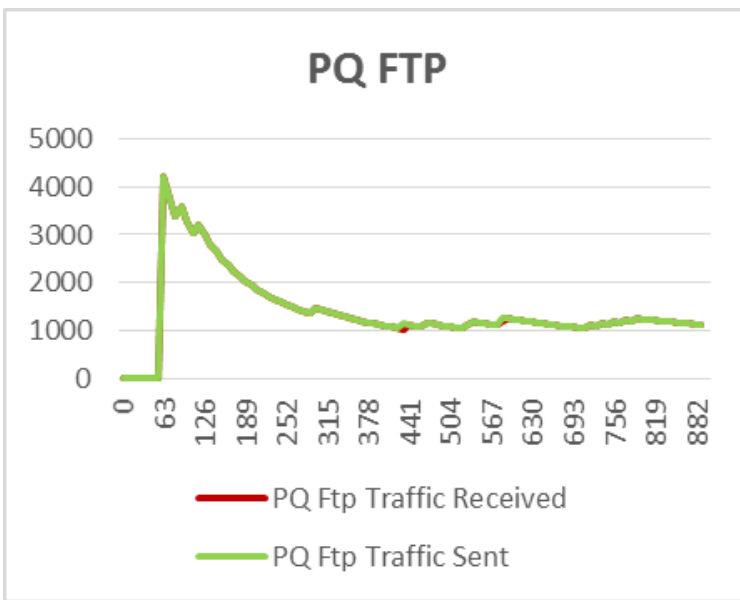

Gambar 4.2 FTP Traffic pada PQ

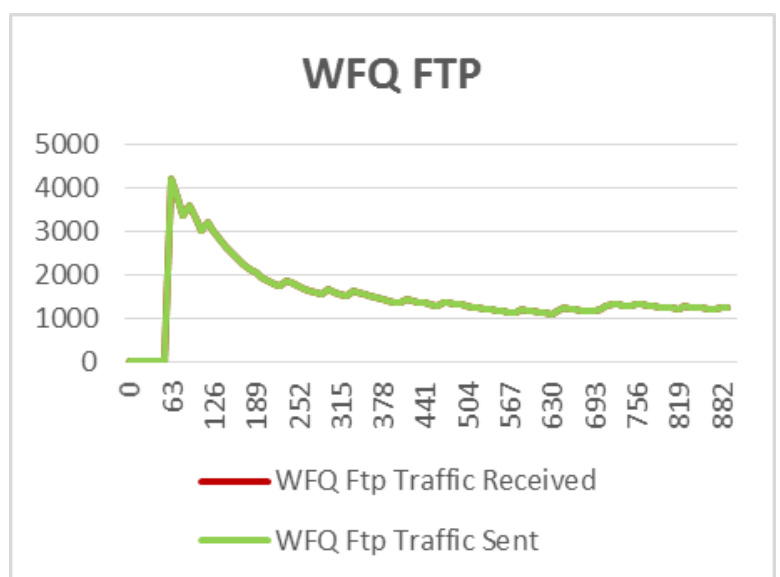

Gambar 4.3 FTP Traffic pada WFQ

Dari grafik tersebut belum terlihat perbedaan antara traffic sent dan traffic received karena nilai keduanya tidak terlalu jauh sehingga grafik menjadi overlap. Untuk dapat melihat dan menghitung nilai packet loss pada layanan FTP maka grafik tersebut dikonversi dan dirata - rata seperti berikut:

\begin{tabular}{|c|c|c|c|}
\hline & $\begin{array}{c}\text { FIFO } \\
\text { (bytes) }\end{array}$ & $\begin{array}{c}\text { PQ } \\
\text { (bytes) }\end{array}$ & $\begin{array}{c}\text { WFQ } \\
\text { (bytes) }\end{array}$ \\
\hline $\begin{array}{c}\text { Traffic } \\
\text { Sent }\end{array}$ & 1354.496484 & 1406.858681 & 1501.051628 \\
\hline $\begin{array}{c}\text { Traffic } \\
\text { Received }\end{array}$ & 1353.911688 & 1404.883143 & 1501.051628 \\
\hline
\end{tabular}

Untuk mendapatkan nilai packet loss maka dilakukan perhitungan kembali dengan menggunakan rumus packet loss.

Packet Loss FIFO

$$
\begin{aligned}
& =\frac{\text { traffic sent }- \text { traffic received }}{\text { traffic sent }} \times 100 \% \\
& =\frac{1354.496484-1353.911688}{1354.496484} \times 100 \% \\
& =0.04317437 \%
\end{aligned}
$$

Packet Loss PQ

$$
=\frac{\text { traffic sent }- \text { traffic received }}{\text { traffic sent }} \times 100 \%
$$$$
=\frac{1406.858681-1404.883143}{1406.858681} \times 100 \%
$$$$
=0.1404219 \%
$$

$$
\begin{aligned}
& \text { Packet Loss WFQ } \\
& =\frac{\text { traffic sent }- \text { traffic received }}{\text { traffic sent }} \times 100 \% \\
& =\frac{1501.051628-1501.051628}{1501.051628} \times 100 \%=0 \%
\end{aligned}
$$

Dengan mengacu pada rumus diatas, maka hasil nilai packet loss adalah berikut: 


\begin{tabular}{|c|c|c|c|}
\hline $\begin{array}{c}\text { FIFO } \\
(\%)\end{array}$ & $\begin{array}{c}\text { PQ } \\
(\%)\end{array}$ & $\begin{array}{c}\text { WFQ } \\
(\%)\end{array}$ & $\begin{array}{c}\text { Standar QoS } \\
(\%)\end{array}$ \\
\hline 0.04317437 & 0.1404219 & 0 & 0 \\
\hline
\end{tabular}

\section{Layanan Video}

\section{Packet Loss}

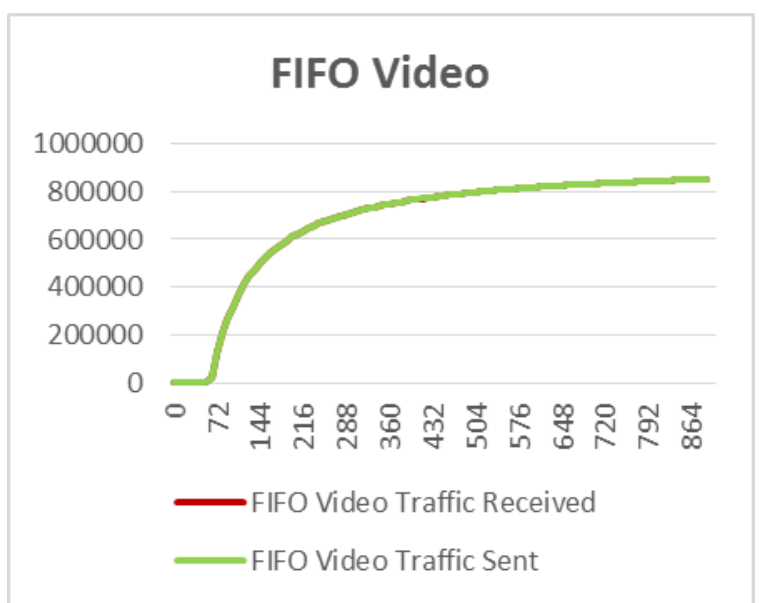

Gambar 4.4 Video Traffic pada FIFO

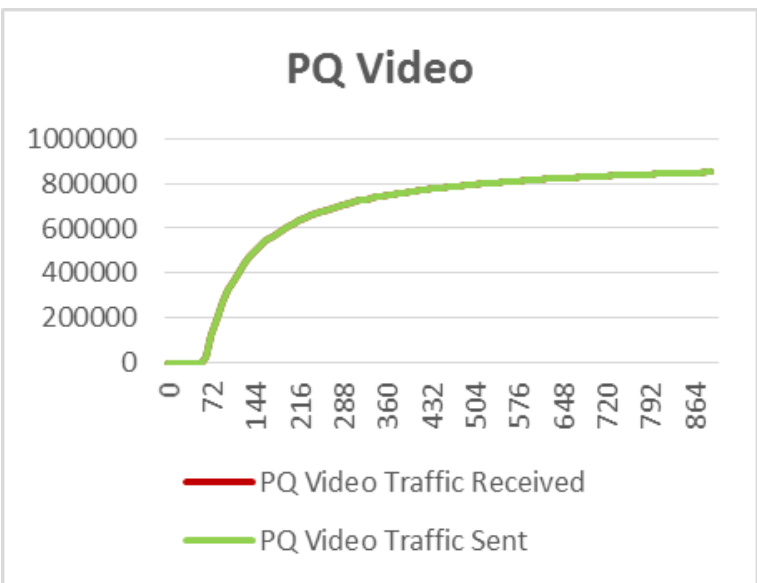

Gambar 4.5 Video Traffic pada PQ

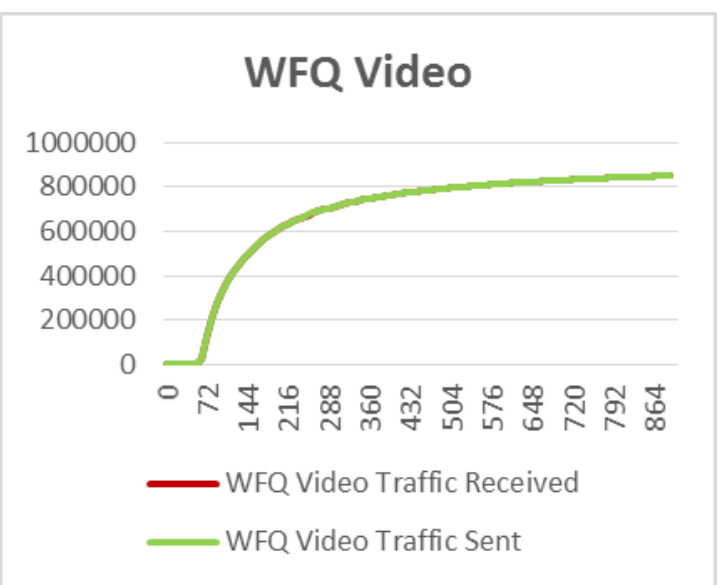

Gambar 4.6 Video Traffic pada WFQ

Dari grafik tersebut belum terlihat perbedaan antara traffic sent dan traffic received karena nilai keduanya tidak terlalu jauh sehingga grafik menjadi overlap. Untuk dapat melihat dan menghitung nilai packet loss pada layanan video maka grafik tersebut akan dikonversi dan dirata - rata seperti berikut:

\begin{tabular}{|c|c|c|c|}
\hline & $\begin{array}{c}\text { FIFO } \\
\text { (bytes) }\end{array}$ & $\begin{array}{c}\text { PQ } \\
\text { (bytes) }\end{array}$ & $\begin{array}{c}\text { WFQ } \\
\text { (bytes) }\end{array}$ \\
\hline $\begin{array}{c}\text { Traffic } \\
\text { Sent }\end{array}$ & 671559.481 & 671559.472 & 671556.7225 \\
\hline $\begin{array}{c}\text { Traffic } \\
\text { Received }\end{array}$ & 671502.0666 & 671501.0745 & 671499.9604 \\
\hline
\end{tabular}

Untuk mendapatkan nilai packet loss maka dilakukan perhitungan kembali dengan menggunakan rumus packet loss.

$$
\begin{aligned}
& \text { Packet Loss FIFO } \\
& =\frac{\text { traffic sent }- \text { traffic received }}{\text { traffic sent }} \times 100 \% \\
& =\frac{671559.481-671502.0666}{671559.481} \times 100 \% \\
& =0.008549414 \% \\
& \text { Packet Loss PQ } \\
& =\frac{\text { traffic sent }- \text { traffic received }}{\text { traffic sent }} \times 100 \% \\
& =\frac{671559.472-671501.0745}{671559.472} \times 100 \% \\
& =0.008695792 \% \\
& \text { Packet Loss WFQ } \\
& =\frac{\text { traffic sent }- \text { traffic received }}{\text { traffic sent }} \times 100 \% \\
& =\frac{671556.7225-671499.9604}{671556.7225} \times 100 \% \\
& =0.008452307 \%
\end{aligned}
$$

Dengan mengacu pada rumus diatas, maka hasil nilai packet loss adalah berikut:

\begin{tabular}{|c|c|c|c|}
\hline $\begin{array}{c}\text { FIFO } \\
(\%)\end{array}$ & $\begin{array}{c}\text { PQ } \\
(\%)\end{array}$ & $\begin{array}{c}\text { WFQ } \\
(\%)\end{array}$ & $\begin{array}{c}\text { Standar QoS } \\
(\%)\end{array}$ \\
\hline 0.008549414 & 0.008695792 & 0.008452307 & $<1$ \\
\hline
\end{tabular}

\section{Delay}




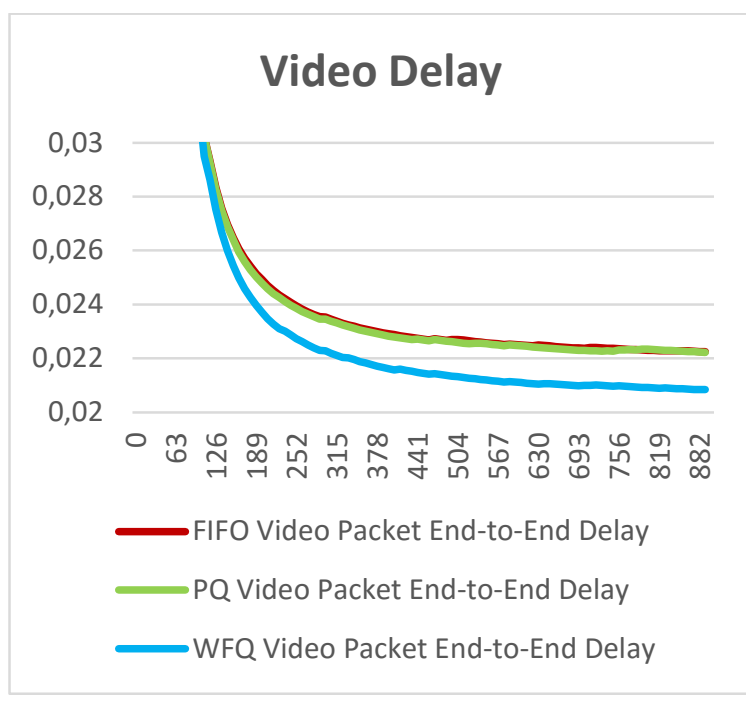

Gambar 4.7 Grafik Perbandingan Video Delay

Apabila grafik tersebut dikonversi dan dirata - rata dengan Microsoft Excel maka dihasilkan berikut:

\begin{tabular}{|c|c|c|c|}
\hline $\begin{array}{c}\text { FIFO } \\
(\mathrm{ms})\end{array}$ & $\begin{array}{c}\text { PQ } \\
(\mathrm{ms})\end{array}$ & $\begin{array}{c}\text { WFQ } \\
(\mathrm{ms})\end{array}$ & $\begin{array}{c}\text { Standar QoS } \\
(\mathrm{ms})\end{array}$ \\
\hline 24.48146779 & 24.4189979 & 23.27930694 & $\begin{array}{c}\text { Istimewa }<150 \\
\text { Limit }<400\end{array}$ \\
\hline
\end{tabular}

\section{Jitter}

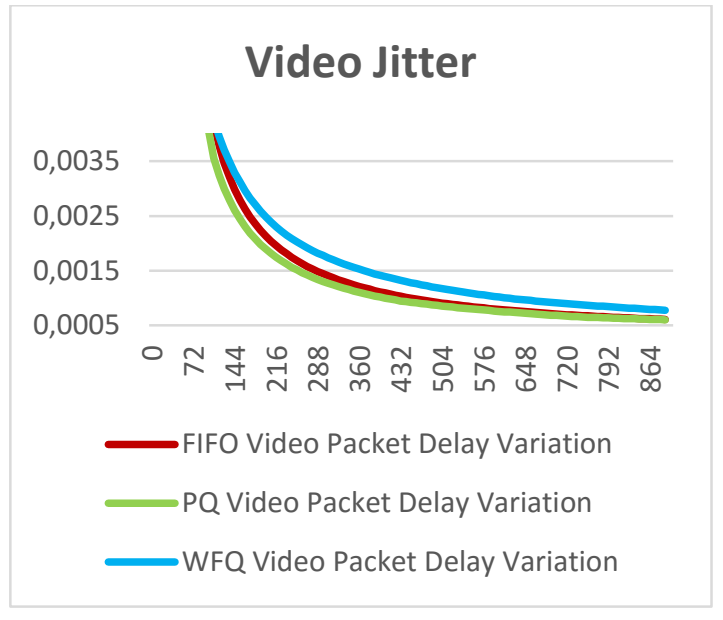

Gambar 4.8 Grafik Perbandingan Video Jitter

Apabila grafik tersebut dikonversi dan dirata - rata dengan Microsoft Excel maka dihasilkan berikut:

\begin{tabular}{|c|c|c|c|}
\hline $\begin{array}{c}\text { FIFO } \\
(\mathrm{ms})\end{array}$ & $\begin{array}{c}\text { PQ } \\
(\mathrm{ms})\end{array}$ & $\begin{array}{c}\text { WFQ } \\
(\mathrm{ms})\end{array}$ & $\begin{array}{c}\text { Standar QoS } \\
(\mathrm{ms})\end{array}$ \\
\hline 1.509691551 & 1.349287122 & 1.732726797 & Unspecified \\
\hline
\end{tabular}

\section{Layanan VoIP \\ Packet Loss}

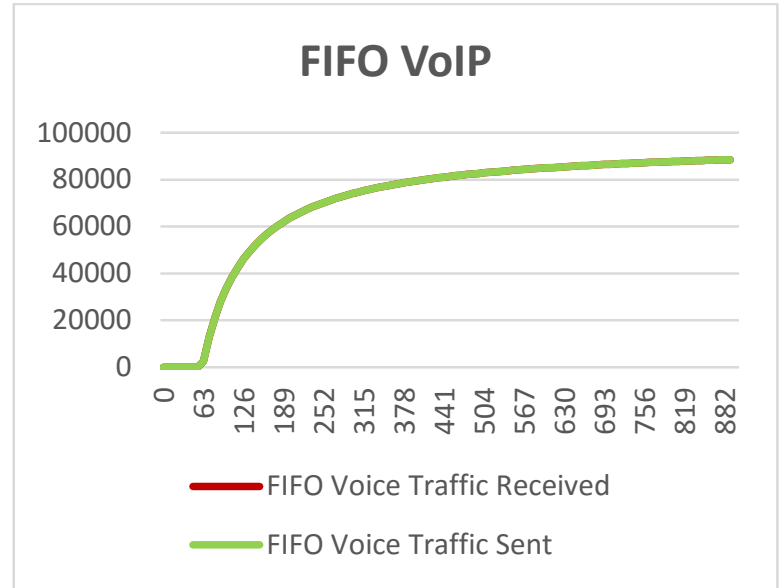

Gambar 4.9 VoIP Traffic pada FIFO

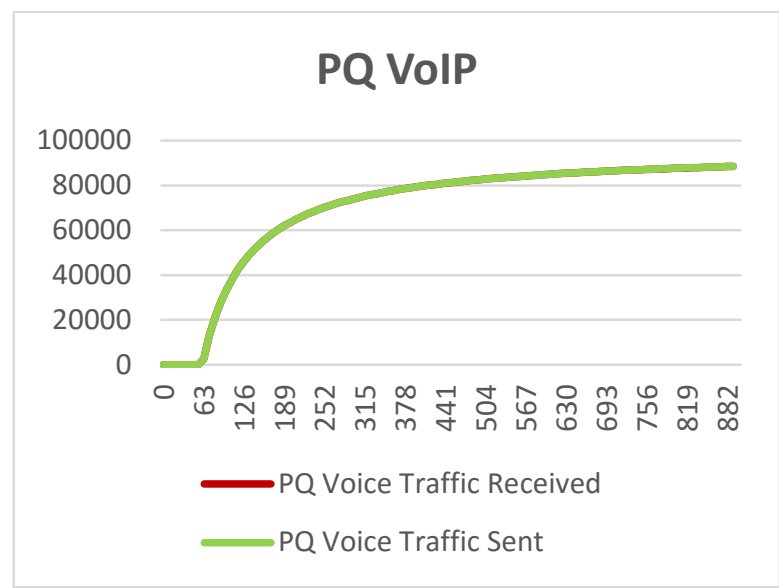

Gambar 4.10 VoIP Traffic pada PQ

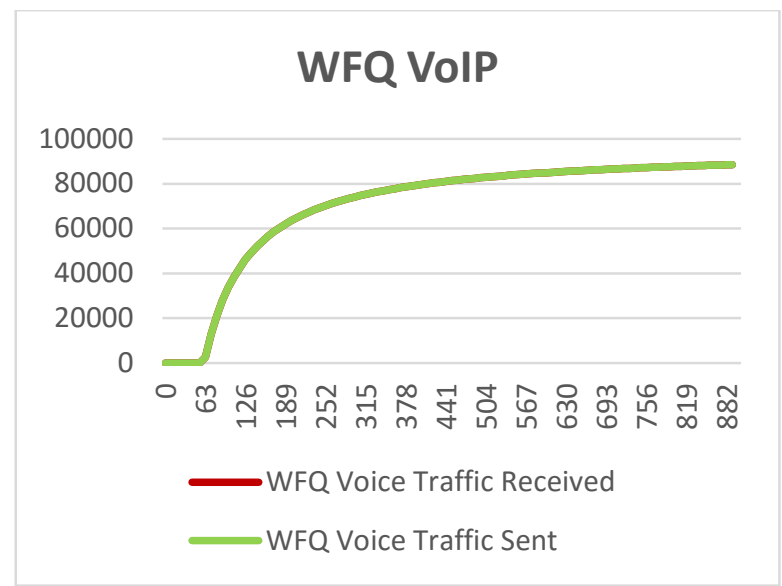

Gambar 4.11 VoIP Traffic pada WFQ

Dari grafik tersebut belum terlihat perbedaan antara traffic sent dan traffic received karena nilai keduanya tidak terlalu jauh sehingga grafik menjadi overlap. Untuk dapat melihat dan menghitung nilai packet loss pada layanan VoIP maka grafik tersebut akan dikonversi dan dirata - rata seperti berikut: 


\begin{tabular}{|c|c|c|c|}
\hline & $\begin{array}{c}\text { FIFO } \\
\text { (bytes) }\end{array}$ & $\begin{array}{c}\text { PQ } \\
\text { (bytes) }\end{array}$ & $\begin{array}{c}\text { WFQ } \\
\text { (bytes) }\end{array}$ \\
\hline $\begin{array}{c}\text { Traffic } \\
\text { Sent }\end{array}$ & 69876.44696 & 69887.97816 & 69887.97816 \\
\hline $\begin{array}{c}\text { Traffic } \\
\text { Received }\end{array}$ & 69875.31194 & 69886.31625 & 69885.49428 \\
\hline
\end{tabular}

Untuk mendapatkan nilai packet loss maka dilakukan perhitungan kembali dengan menggunakan rumus packet loss.

$$
\begin{aligned}
& \text { Packet Loss FIFO } \\
& =\frac{\text { traffic sent }- \text { traffic received }}{\text { traffic sent }} \times 100 \% \\
& =\frac{69876.44696-69875.31194}{69876.44696} \times 100 \% \\
& =0.001624319 \% \\
& \text { Packet Loss PQ } \\
& =\frac{\text { traffic sent }- \text { traffic received }}{\text { traffic sent }} \times 100 \% \\
& =\frac{69887.97816-69886.31625}{69887.97816} \times 100 \% \\
& =0.002377956 \% \\
& =\frac{\text { traffic sent }- \text { traffic received }}{\text { traffic sent }} \times 100 \% \\
& =\frac{69887.97816-69885.49428}{69887.97816} \times 100 \% \\
& =0.003554089 \%
\end{aligned}
$$

Dengan mengacu pada rumus diatas, maka hasil nilai packet loss adalah berikut:

\begin{tabular}{|c|c|c|c|}
\hline $\begin{array}{c}\text { FIFO } \\
(\%)\end{array}$ & $\begin{array}{c}\text { PQ } \\
(\%)\end{array}$ & $\begin{array}{c}\text { WFQ } \\
(\%)\end{array}$ & $\begin{array}{c}\text { Standar QoS } \\
(\%)\end{array}$ \\
\hline 0.001624319 & 0.002377956 & 0.003554089 & $<3$ \\
\hline
\end{tabular}

\section{Delay}

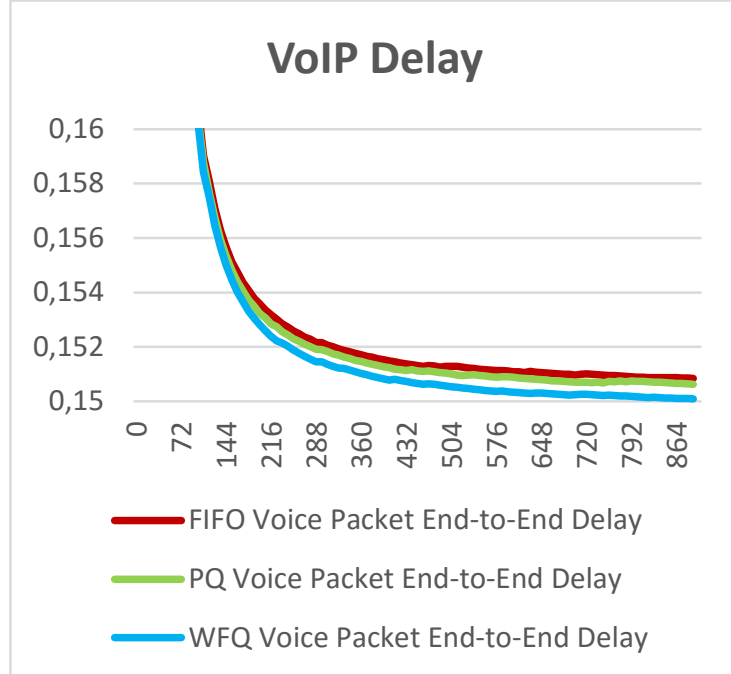

Gambar 4.12 Grafik Perbandingan VoIP Delay
Apabila grafik tersebut dikonversi dan dirata - rata dengan Microsoft Excel maka dihasilkan berikut:

\begin{tabular}{|c|c|c|c|}
\hline $\begin{array}{c}\text { FIFO } \\
(\mathrm{ms})\end{array}$ & $\begin{array}{c}\text { PQ } \\
(\mathrm{ms})\end{array}$ & $\begin{array}{c}\text { WFQ } \\
(\mathrm{ms})\end{array}$ & $\begin{array}{c}\text { Standar QoS } \\
(\mathrm{ms})\end{array}$ \\
\hline 153.1331874 & 152.8649658 & 152.4203519 & $\begin{array}{c}\text { Istimewa }<150 \\
\text { Limit }<400\end{array}$ \\
\hline
\end{tabular}

\section{Jitter}

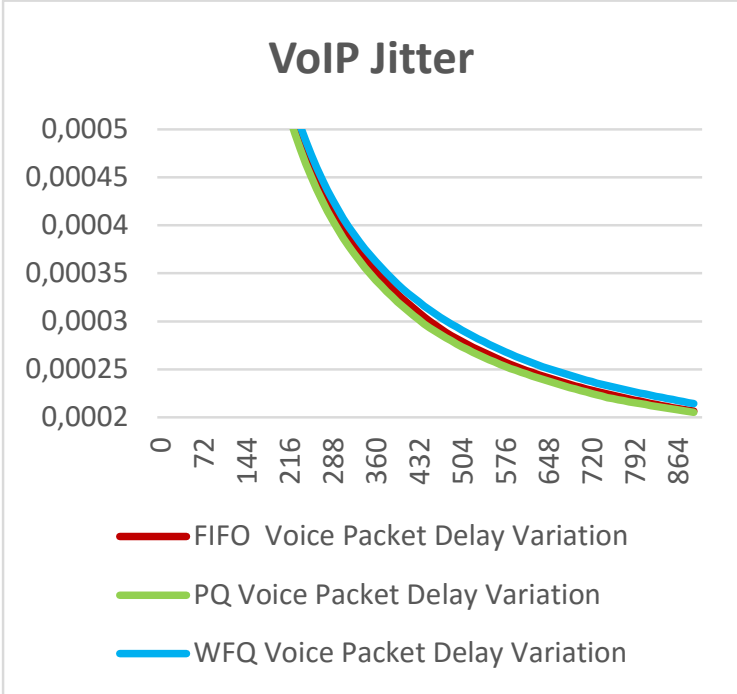

Gambar 4.13 Grafik Perbandingan VoIP Jitter

Apabila grafik tersebut dikonversi dan dirata - rata dengan Microsoft Excel maka dihasilkan berikut:

\begin{tabular}{|c|c|c|c|}
\hline $\begin{array}{c}\text { FIFO } \\
(\mathrm{ms})\end{array}$ & $\begin{array}{c}\text { PQ } \\
(\mathrm{ms})\end{array}$ & $\begin{array}{c}\text { WFQ } \\
(\mathrm{ms})\end{array}$ & $\begin{array}{c}\text { Standar QoS } \\
(\mathrm{ms})\end{array}$ \\
\hline 0.40906986 & 0.402179261 & 0.425769976 & $<1$ \\
\hline
\end{tabular}

\section{SIMPULAN}

Berdasarkan hasil data simulasi yang telah diperoleh dan dianalisa, maka dapat dibuat beberapa kesimpulan sebagai berikut:

1. Layanan non real time seperti FTP lebih efektif diberikan bobot paket pada skema antrian WFQ dibanding skema antrian dengan algoritma sederhana seperti FIFO dan PQ yang memungkinkan adanya packet loss, penggunaan skema antrian juga efektif menurunkan nilai delay dan jitter pada layanan video dan VoIP terlihat pada grafik yang menurun dari waktu awal ke akhir.

2. Secara keseluruhan skema antrian WFQ memenuhi nilai QoS packet loss, delay, dan jitter yang paling baik pada semua layanan, yang berarti pemberian bobot paket $50 \%$ pada video, $40 \%$ pada VoIP, dan 10\% pada FTP terbukti efektif untuk perancangan topologi dan konfigurasi yang dibuat.

3. Hasil skema antrian pada ketiga skenario yaitu FIFO, PQ, dan WFQ secara umum sudah 
memenuhi standar QoS yang dikeluarkan oleh ETSI maupun ITU, namun delay pada layanan VoIP memiliki nilai sedikit diatas standar istimewa tetapi masih jauh dibawah dari standar limit yang ditentukan.

\section{DAFTAR PUSTAKA}

ETSI. (1999). Telecommunications and Internet Protocol Harmonization over Networks: General of Quality of Service.

ITU-T. (2001). Series G: Transmission Systems and Media, Digital Systems and Networks Quality of Service.

Semeria, Chunk. (2001). White Paper Supporting Differentiated Service Classes: Queue Scheduling Disciplines. USA: Juniper Network Inc.

Cahyadi, Eko Fajar. (2013). Perhitungan Kesiapan Jaringan IP Untuk Mendukung Layanan H.232 Dekstop Video conferencing Dalam Beberapa Disiplin Antrian Menggunakan OPNET. Bandung : Institut Teknologi Bandung.

Sulistiyo, Rosdian Ardi. (2015). Analisa Karakteristik Teori Antrian Pada Teknologi Switching Asynchronous Transfer Mode Menggunakan OPNET Modeler 14.5. Purwokerto: Sekolah Tinggi Teknologi Telematika Telkom. 